University of New Hampshire

University of New Hampshire Scholars' Repository

$5-27-2010$

\title{
Evidence of nitric acid uptake in warm cirrus anvil clouds during the NASA TC4 campaign
}

\author{
Eric Scheuer \\ University of New Hampshire - Main Campus, Eric.Scheuer@unh.edu \\ Jack E. Dibb \\ University of New Hampshire, jack.dibb@unh.edu \\ Cynthia Twohy \\ Oregon State University \\ David Rogers \\ Oregon State University \\ Andrew J. Heymsfield \\ NCAR
}

See next page for additional authors

Follow this and additional works at: https://scholars.unh.edu/earthsci_facpub

Part of the Atmospheric Sciences Commons

\section{Recommended Citation}

Scheuer, E., J. E. Dibb, C. Twohy, D. C. Rogers, A. J. Heymsfield, and A. Bansemer (2010), Evidence of nitric acid uptake in warm cirrus anvil clouds during the NASA TC4 campaign, J. Geophys. Res., 115, D00J03, doi:10.1029/2009JD012716.

This Article is brought to you for free and open access by the Earth Sciences at University of New Hampshire Scholars' Repository. It has been accepted for inclusion in Earth Sciences Scholarship by an authorized administrator of University of New Hampshire Scholars' Repository. For more information, please contact Scholarly.Communication@unh.edu. 


\section{Authors}

Eric Scheuer, Jack E. Dibb, Cynthia Twohy, David Rogers, Andrew J. Heymsfield, and Aaron Bansemer 


\title{
Evidence of nitric acid uptake in warm cirrus anvil clouds during the NASA TC4 campaign
}

\author{
Eric Scheuer, ${ }^{1}$ Jack E. Dibb, ${ }^{1}$ Cynthia Twohy, ${ }^{2}$ David C. Rogers, ${ }^{3}$ Andrew J. Heymsfield, ${ }^{4}$ \\ and Aaron Bansemer ${ }^{4}$ \\ Received 24 June 2009; revised 3 December 2009; accepted 18 December 2009; published 15 June 2010.
}

[1] Uptake of $\mathrm{HNO}_{3}$ onto cirrus ice may play an important role in tropospheric $\mathrm{NO}_{\mathrm{x}}$ cycling. Discrepancies between modeled and in situ measurements of gas-phase $\mathrm{HNO}_{3}$ in the troposphere suggest that redistribution and removal mechanisms by cirrus ice have been poorly constrained. Limited in situ measurements have provided somewhat differing results and are not fully compatible with theory developed from laboratory studies. We present new airborne measurements of $\mathrm{HNO}_{3}$ in cirrus clouds from anvil outflow made during the Tropical Composition, Cloud, and Climate Coupling Experiment (TC4). Upper tropospheric $(>9 \mathrm{~km})$ measurements made during three flights while repeatedly traversing the same cloud region revealed depletions of gas-phase $\mathrm{HNO}_{3}$ in regions characterized by higher ice water content and surface area. We hypothesize that adsorption of $\mathrm{HNO}_{3}$ onto cirrus ice surfaces could explain this. Using measurements of cirrus ice surface area density and some assumptions about background mixing ratios of gas-phase $\mathrm{HNO}_{3}$, we estimate molecular coverages of $\mathrm{HNO}_{3}$ on cirrus ice surface in the tropical upper troposphere during the TC4 racetracks to be about $1 \times 10^{13}$ molecules $\mathrm{cm}^{-2}$. This likely reflects an upper limit because potential dilution by recently convected, scavenged air is ignored. Also presented is an observation of considerably enhanced gas-phase $\mathrm{HNO}_{3}$ at the base of a cirrus anvil suggesting vertical redistribution of $\mathrm{HNO}_{3}$ by sedimenting cirrus particles and subsequent particle sublimation and $\mathrm{HNO}_{3}$ evaporation. The impact of released $\mathrm{HNO}_{3}$, however, appears to be restricted to a very thin layer just below the cloud.

Citation: Scheuer, E., J. E. Dibb, C. Twohy, D. C. Rogers, A. J. Heymsfield, and A. Bansemer (2010), Evidence of nitric acid uptake in warm cirrus anvil clouds during the NASA TC4 campaign, J. Geophys. Res., 115, D00J03, doi:10.1029/2009JD012716.

\section{Introduction}

[2] Gas-phase nitric acid, $\mathrm{HNO}_{3}$, is a primary reservoir species of atmospheric nitrogen oxides $\left(\mathrm{NO}_{\mathrm{x}}=\mathrm{NO}+\mathrm{NO}_{2}\right)$ [Neuman et al., 2001; Staudt et al., 2003] which play an important role in upper tropospheric ozone production [Jacob et al., 1996]. Early global chemistry models generally over predicted upper tropospheric (UT) $\mathrm{HNO}_{3}$ by factors ranging from two to ten [Thakur et al., 1999] suggesting, in part, that removal mechanisms were poorly understood. Recent implementations of the GEOS-Chem

\footnotetext{
${ }^{1}$ Institute for the Study of Earth, Oceans and Space, University of New Hampshire, Durham, New Hampshire, USA.

${ }^{2}$ College of Oceanic and Atmospheric Sciences, Oregon State University, Corvallis, Oregon, USA.

${ }^{3}$ Research Aviation Facility, National Center for Atmospheric Research, Broomfield, Colorado, USA.

${ }^{4}$ Earth and Sun Systems Laboratory, National Center for Atmospheric Research, Boulder, Colorado, USA.
}

Copyright 2010 by the American Geophysical Union. 0148-0227/10/2009JD012716 and RAQMS models by Hudman et al. [2007] and Pierce et al. [2007] showed significant improvement, but still generally overestimate upper $\mathrm{UT}_{\mathrm{HNO}_{3}}$ when compared to aircraft measurements. Lawrence and Crutzen [1998] suggested that efficient removal by adsorptive uptake onto cirrus cloud ice particles and subsequent gravitational sedimentation had the potential to significantly redistribute or remove $\mathrm{HNO}_{3}$ in the UT explaining some of the discrepancies between measurements and models. Initial laboratory investigations into $\mathrm{HNO}_{3}$ uptake onto ice surfaces found that this process is efficient, and appears to proceed until there is a high fractional surface coverage of available adsorption sites. However, details of the uptake have varied between experiments using ice particles and films, and may be less than ideal surrogates for crystals in cirrus clouds. Also, most of these experiments were performed using $\mathrm{HNO}_{3}$ partial pressures greatly in excess of those likely in the UT requiring large and poorly constrained extrapolations to relevant vapor pressures [Abbatt, 1997; Zondlo et al., 1997; Arora et al., 1999; Hudson et al., 2002; Hynes et al., 2002]. Tabazadeh et al. [1999] assessed the results of several lab studies and presented a Langmuir surface chemical model that assumed the isotherm was dissociative and concluded that uptake of 
$\mathrm{HNO}_{3}$ onto cirrus may be nearly an order of magnitude less efficient than Lawrence and Crutzen [1998] assumed. Tabazadeh et al. [1999] also suggested that sublimation of cirrus crystals within several kilometers below clouds would limit the extent of vertical redistribution of $\mathrm{HNO}_{3}$ by this process. A box model employed by Meier and Hendricks [2002] expanded on the assumptions by Tabazadeh et al. [1999] for a much wider range of ambient conditions and sedimentation efficiencies and that suggested under some conditions $\mathrm{HNO}_{3}$ uptake on cirrus ice and gravitational sedimentation could still be an efficient denitrification mechanism. Laboratory studies by Ullerstam et al. [2005] were the first to be performed at $\mathrm{HNO}_{3}$ lower partial pressures more typical of the UT and confirmed some aspects of prior studies. $\mathrm{HNO}_{3}$ uptake on ice surfaces in these experiments was found to be positively correlated with overlying $\mathrm{HNO}_{3}$ partial pressures, and negatively correlated with temperature. However, surface coverage was found to be far from a complete molecular monolayer at partial pressures of $\mathrm{HNO}_{3}$ typical of the UT, and uptake followed conventional nondissociative Langmuir isotherm. Ullerstam et al. [2005] also noted that conventional and nondissociative Langmuir treatments of $\mathrm{HNO}_{3}$ uptake on ice predict similar behavior at high vapor pressures but diverged markedly at low pressures.

[3] The first in situ aircraft measurements to provide evidence for uptake of $\mathrm{HNO}_{3}$ by cirrus ice were reported by Weinheimer et al. [1998]. They measured the sum of condensed-phase plus gas-phase $\mathrm{NO}_{\mathrm{y}}$ through a forward facing inlet compared to a gas-phase only rear facing inlet to infer that up to $20 \%$ of $\mathrm{NO}_{\mathrm{y}}$ was adsorbed onto ice in a mountain wave cloud over Colorado. Nitric acid was assumed to be the only component of $\mathrm{NO}_{\mathrm{y}}$ taken up by ice. Surface coverages on the cirrus crystals were later estimated to be in the range of $1-4 \times 10^{13}$ molecules $\mathrm{cm}^{-2}$ for measurements made near the tropopause at $\sim 215 \mathrm{~K}$ [Hudson et al., 2002]. Several subsequent aircraft studies have also used similar dual inlet equipped $\mathrm{NO}_{\mathrm{y}}$ instruments to "observe" $\mathrm{HNO}_{3}$ on ice crystals in the UT. Meilinger et al. [1999] estimated coverages of $1 \times 10^{13}$ molecules $\mathrm{cm}^{-2}$ in Arctic cirrus at $\sim 196 \mathrm{~K}$, much lower than estimates near $2 \times 10^{14}$ molecules $\mathrm{cm}^{-2}$ reported by Kondo et al. [2003] in Arctic clouds at temperatures $\sim 210 \mathrm{~K}$. Extensive measurements at midlatitudes reported by Ziereis et al. [2004] indicate coverages in the range 1$10 \times 10^{13}$ and $0.5-1.5 \times 10^{13}$ molecules $\mathrm{cm}^{-2}$ at 214 and $227 \mathrm{~K}$, respectively. In both cases, the inferred vapor pressure of $\mathrm{HNO}_{3}$ corresponding to the high end of the estimated molecular coverage range was a factor of four greater than estimates for the low end of the range. Direct measurements of condensed-phase and gas-phase $\mathrm{HNO}_{3}$ in subtropical cirrus during the NASA CRYSTAL-FACE campaign are presented by Popp et al. [2004]. These data were also obtained with a similar dual inlet arrangement, but $\mathrm{HNO}_{3}$ was quantified directly by chemical ionization mass spectrometry (CIMS) rather than inferred from $\mathrm{NO}_{\mathrm{y}}$ measurements. Mean surface coverages of $6 \times 10^{13}$ molecules $\mathrm{cm}^{-2}$ at $198 \mathrm{~K}$ and about $2 \times 10^{13}$ molecules $\mathrm{cm}^{-2}$ for four $5 \mathrm{~K}$ bins from 200-220 K were estimated. Popp et al. [2004] suggested that the samples at temperatures below $200 \mathrm{~K}$ were impacted by nitric acid trihydrate (NAT), thus not truly comparable to cirrus ice and point out that the rest of their observations indicate very weak, or no, dependence on tem- perature. Ullerstam et al. [2005] compared the results of these different field studies and suggested that overall the studies on thin ice films in flow tubes were qualitatively consistent and concluded that $\mathrm{HNO}_{3}$ uptake in real clouds should generally increase at higher $\mathrm{HNO}_{3}$ vapor pressures and at lower temperatures (though the Meilinger et al. [1999] results do not fit this generalization with very low estimated surface coverages at cold temperatures). They also noted, however, that when a conventional nondissociative Langmuir isotherm model fitted to their laboratory results was used to estimate surface coverages at the conditions of the various field studies, observed values were generally smaller than the estimates.

[4] In this paper, we report the first field evidence for uptake of $\mathrm{HNO}_{3}$ onto tropical cirrus crystals in the intertropical convergence zone (ITCZ) near Costa Rica using measurements of gas-phase $\mathrm{HNO}_{3}$, ice water content (IWC), and surface area density (SAD). These observations extend the temperature range of in situ studies nearly to $245 \mathrm{~K}$ and explore quite low $\mathrm{HNO}_{3}$ vapor pressures. Simultaneous measurements of condensed-phase $\mathrm{HNO}_{3}$ are not available, adding uncertainty to our quantitative estimates of $\mathrm{HNO}_{3}$ surface coverage on ice, but we suggest the estimates are still informative because they are based on observations in quite warm cirrus several kilometers below the tropopause.

\section{Methods}

\subsection{TC4 Mission}

[5] NASA's Tropical Composition, Cloud and Climate Coupling (TC4) experiment in July and August 2007 deployed the DC-8, ER-2 and WB-57 aircraft to Costa Rica to study deep convection in the ITCZ and its impact on the tropical tropopause layer (TTL) [Toon et al., 2010]. The primary role of the DC-8 was expected to be characterizing the chemical and microphysical properties of the troposphere to constrain the composition of air being entrained into the convection. However, during flights much of the convective outflow and resulting cirrus near Costa Rica during the campaign was close to the $13 \mathrm{~km}$ ceiling of the DC-8. As a result, roughly half of all DC-8 sampling time targeted the UT $(9-13 \mathrm{~km})$ and most of that time was in and near cirrus clouds. Here we report on observations of in situ $\mathrm{HNO}_{3}, \mathrm{IWC}$, and SAD during three flights that targeted cirrus shields from specific convective cores to examine the extent of depletion of gas-phase $\mathrm{HNO}_{3}$ by uptake on ice crystals in these clouds.

\section{2. $\mathrm{HNO}_{3}$ Measurements}

[6] Gas-phase nitric acid was measured with the University of New Hampshire automated dual mist chamber/ion chromatograph system (MC/IC). In this system, ambient air is drawn into the aircraft at high velocity through a short $(<1 \mathrm{~m})$, Silcosteel ${ }^{\circledR}$ (Restek, Inc., Bellefonte, Pennsylvania) coated manifold at approximately $3 \mathrm{~m}^{3}$ (volumetric) $\mathrm{min}^{-1}$. Ambient air is subsampled at approximately $45-50 \mathrm{~L} \mathrm{~min}^{-1}$ (volumetric) by one of a pair of glass mist chambers mounted on the high flow manifold. The mist chamber inlets are rear facing with respect to the flow in the manifold which, based on stopping distance calculations from Hinds [1982], should effectively exclude particles greater than 


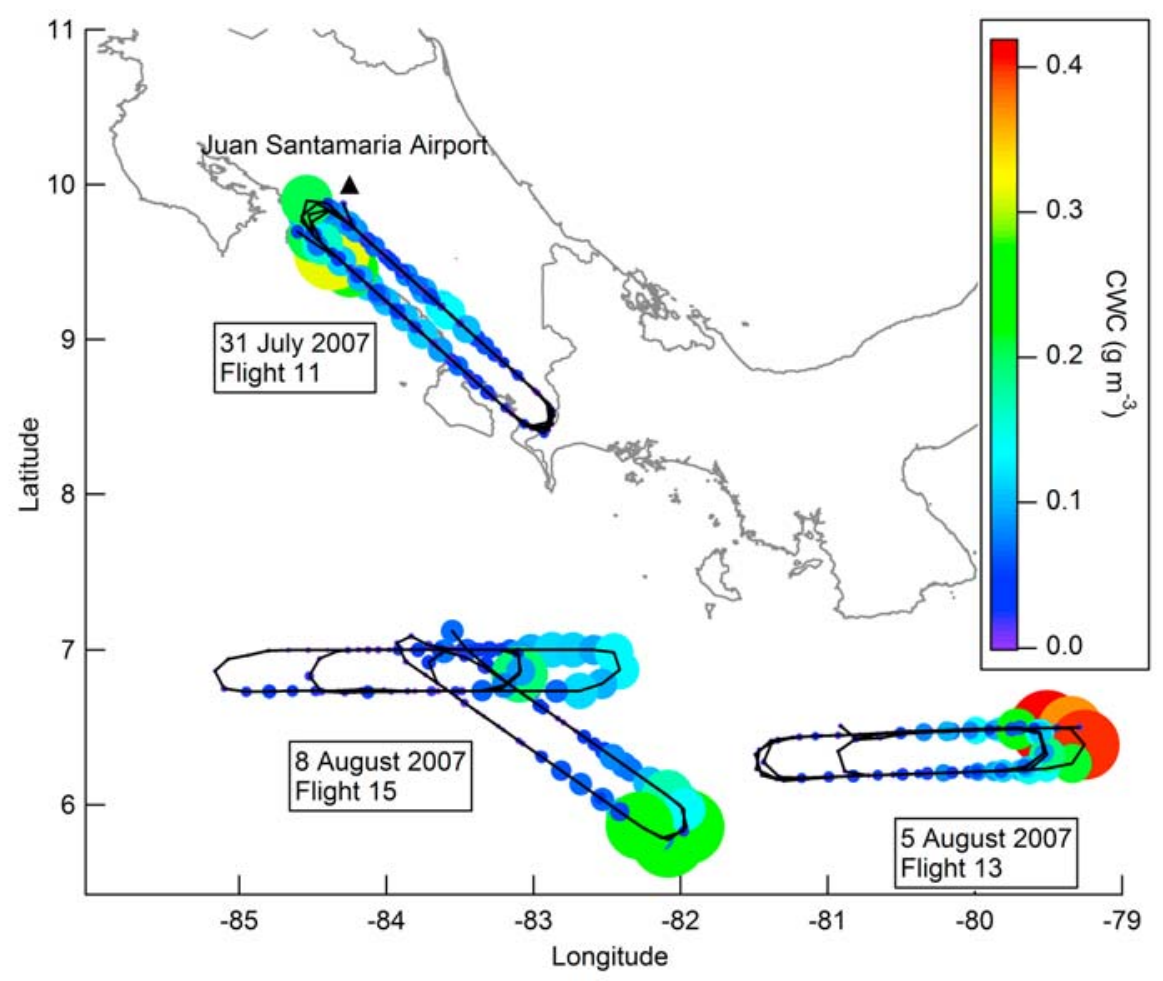

Figure 1. Map of racetrack maneuvers during TC4 flights on 31 July and 5 and 8 August. Circles represent measurements of condensed water content in $\mathrm{g} \mathrm{m}^{-3}$ averaged to the $\mathrm{HNO}_{3}$ measurement integration time and show progression of aircraft in and out of heavy cirrus cloud.

$\sim 1 \mu \mathrm{m}$. Discrete samples integrated for approximately $85 \mathrm{~s}$ are alternately collected by each mist chamber. While one mist chamber is sampling, the preceding sample collected in the other mist chamber is injected into an ion chromatograph where $\mathrm{HNO}_{3}$ is detected as the $\mathrm{NO}_{3}^{-}$ion. $\mathrm{HNO}_{3}$ detection limits varied inversely with the mist chamber mass flow rate which decreases with altitude, but were typically better than 3 parts per trillion by volume (pptv). Overall measurement uncertainty of $\mathrm{HNO}_{3}$ for values less than 25 pptv is believed to be $30-35 \%$; about $20 \%$ for values between 25 and 100 pptv, and $15 \%$ for values above 100 pptv. Variants of this instrument have been flown on the DC-8 on more than 10 other campaigns (TRACE-A, PEM-WEST A and B, PEM-TROPICS A and B, SONEX, PAVE, TRACE-P, INTEX A and B, ARCTAS).

\subsection{Ice Water Content Measurements}

[7] Ice water content (IWC) in cirrus cloud was measured using the National Center for Atmospheric Research (NCAR) counterflow virtual impactor (CVI) as described by Twohy et al. [1997]. Ice crystals with aerodynamic diameters greater than about 5 microns are separated from interstitial air using dry nitrogen counter flow at the inlet tip of the forward facing inlet. A tunable diode laser hygrometer is used to measure the water content after ice crystals are evaporated within the inlet. Uncertainty in individual measurements is typically about $15 \%$, but varies with measurement magnitude and can be considerably higher at very low values. For example, for IWC values near $0.5 \mathrm{~g} \mathrm{~m}^{3}$, uncertainty is $11-13 \%$ and for IWC values of $0.005 \mathrm{~g} \mathrm{~m}^{3}$ uncertainty is $15-24 \%$.

\subsection{Ice Surface Area Density Measurements}

[8] Particle size distributions (PSD) were measured by two-dimensional cloud and precipitation imaging probes (CIP, PIP) covering the size range from about 50 to 3000 microns. Projected areas given by the 2-D images of the particles were measured, which, together with the PSD's, gave distributions of particle cross-sectional area per unit volume. It was desirable to average the $2-\mathrm{D}$ probe data over $5 \mathrm{~s}$ intervals to ensure that sufficient numbers of particles $1 \mathrm{~mm}$ and above, normally present in low concentrations, were obtained. The 2-D probe data have been processed objectively to remove artifacts produced by shattering on the probes' leading edges [see Field et al., 2006]. While difficult to constrain, individual SAD measurements are believed to accurate to $+/-\sim 25 \%$.

[9] All data and analyses presented here are temporally merged where the IWC and SAD observations are averaged over the integration time of each mist chamber sample. All original data are available from the NASA Earth Science Project Office (ESPO) archive.

\section{Results}

[10] We focus on three flights conducted on 31 July and 5 and 8 August 2007. During these flights, extended periods of time were spent flying in orbital "racetrack" patterns within cirrus clouds (Figure 1). The purpose of the race- 
tracks was to observe the evolution of cloud microphysical characteristics as measured by a number of in situ sensors on the DC-8 and by remote sensors deployed on the ER-2 which simultaneously conducted the same racetrack flight patterns above the clouds [e.g., Jensen et al., 2009; Tian et al., 2010]. The straight legs of each oval were typically about $20 \mathrm{~min}$ long $(\sim 200 \mathrm{~km})$ with the turns at each end making the horizontal extent of each oval roughly $250 \mathrm{~km}$. The tangent point of upwind turns were set up in real time to be about $10 \mathrm{~km}$ downwind of the convective turret of a cirrus anvil identified by the flight planning team at base from rapid-update GOES imagery. The 31 July flight targeted cirrus clouds streaming to the southeast from a convective complex that was visible from the operations base at Juan Santamaria airport near San Jose, Costa Rica. Remote sensing observations from both the DC-8 and the ER-2 suggest that the peak convective outflow was above the DC -8 ceiling, thus the in situ observations were in the lower part of the cirrus anvil. On the 5 and 8 August flights the cirrus anvils extended westward from the convective cores selected. On these flights the DC-8 was unable to reach cloud tops but was able to get near to the top of the cirrus in later orbits. Seven complete orbits were flown on the 31 July flight, and five complete orbits were flown on each of the 5 and 8 August flights (Figure 1). It should be noted that during the 8 August flight the convective core feeding the initially selected cirrus anvil dissipated, so the pattern was moved to fly in a newly formed anvil nearby. It should also be noted that the DC- 8 flew all of these orbits at the highest altitude safely obtainable, limited by aircraft weight. The altitude slowly increased as fuel was consumed and aircraft weight decreased as can be seen in Figure 2. This provided an opportunity to sample each cloud at a range of temperatures, decreasing from nearly $245 \mathrm{~K}$ for early passes to about $220 \mathrm{~K}$ for the later passes for each flight.

[11] During the cirrus cloud orbits on all three flights, $\mathrm{HNO}_{3}$ generally oscillated between about 5 to nearly 75 pptv with the exception of large enhancements around $t=55,500$ $56,500 \mathrm{~s}$ and $t=59,000 \mathrm{~s}$ during the 31 July flight (Figures 24). The first large enhancement was observed on the 31 July flight when the aircraft briefly descended below the visible cloud base (discussed in section 4.3) and the second was during the turn at the far southeastern end of an orbit where the cirrus was thin and patchy (Figure 2a). In general, the lowest $\mathrm{HNO}_{3}$ mixing ratios of each orbit were observed at the upwind end of each orbit (closer to the cloud turret) and highest mixing ratios were at the downwind end. When orbits were repeated at constant altitude the variations of $\mathrm{HNO}_{3}$ with respect to position were quite similar in successive passes over the established track. This is most clearly seen after $t=53,000 \mathrm{~s}$ on the 5 August flight (Figure 2b). The trend in IWC was opposite in this orbit-scale pattern compared to $\mathrm{HNO}_{3}$, being highest at the upwind end near the convective core (where $\mathrm{HNO}_{3}$ was lowest) and decreasing downwind (Figure 2). Increases in IWC over shorter time intervals (smaller spatial scales) often coincided with decreased $\mathrm{HNO}_{3}$ mixing ratios as well.

\section{Discussion}

\subsection{General Observations}

[12] Mixing ratios of $\mathrm{HNO}_{3}$ were significantly depressed in cirrus clouds sampled during TC4 compared to the mean mixing ratio of $120 \mathrm{pptv}$ for all out of cloud measurements in the same 9-13 km upper tropospheric altitude range. Two processes may contribute to the lower mixing ratios. First, some fraction of the air inside the clouds may represent recent convectively pumped air in which $\mathrm{HNO}_{3}$ could have been scavenged by precipitation in the updraft [e.g., Bertram et al., 2007], and second, cirrus ice crystals may have adsorbed $\mathrm{HNO}_{3}$ in the UT surrounding the convective outflow. The anticorrelation with IWC (Figure 2), sometimes observed over short time periods (e.g., Figure 2c, $\sim t=49,000)$, suggests that the latter process plays an important role. Likewise, the sharp increase in $\mathrm{HNO}_{3}$ mixing ratios observed during the dip below the visible cloud base at $t=55,300$ to $t=56,500(\sim 9.5 \mathrm{~km})$ on the 31 July flight (Figures $2 \mathrm{a}$ and 4 ) appears to reflect a release of $\mathrm{HNO}_{3}$ from evaporating cirrus ice crystals. Such release suggests that there had to be considerable $\mathrm{HNO}_{3}$ uptake by the cirrus ice. The fact that the DC- 8 was often below the altitude of peak outflow in cirrus that had fallen out of the thickest part of the anvil would imply that a significant fraction of the sampled air surrounding the ice crystals had not been recently convected. Also, the observed increases of $\mathrm{HNO}_{3}$ in thinner downwind regions of the study region have to reflect contributions of nonconvected UT air because $\mathrm{HNO}_{3}$ would not have been produced so quickly in detraining air depleted by scavenging [Bertram et al., 2007]. In a tracer study of this region, M. Avery et al. (Convective distribution of tropospheric ozone and tracers in the Central American ITCZ region: Evidence from observations during TC4, submitted to Journal of Geophysical Research, 2010) conclude that the UT study region could represent an even mix of background long-range transport pollution and air convected from $\sim 2-3 \mathrm{~km}$ above the MBL, but not from the MBL directly. We assume that the observed depletions of $\mathrm{HNO}_{3}$ are strongly influenced by uptake onto the cirrus crystals as the anvil detrained into UT air and/or the ice crystals settled into UT air below the altitude of maximum convective outflow.

\subsection{Evidence for $\mathrm{HNO}_{3}$ Uptake Onto Cirrus Ice Particles}

[13] The premise that $\mathrm{HNO}_{3}$ was depleted in cirrus clouds is based on comparisons to background observations made in cloud-free air at 9-12 km altitude during TC4. For quantification, a background needs to be defined. A mean mixing ratio of $\sim 60$ pptv was observed in UT clear air in the immediate vicinity of the racetracks during these three flights. This air, so close to strong convection, may contain a significant fraction of cloud processed air and represent too

Figure 2. Time series measurements made during the racetrack maneuvers of gas-phase $\mathrm{HNO}_{3}$ mixing ratios (solid black) and condensed water content (solid gray) averaged to $\mathrm{HNO}_{3}$ instrument integration time on the (a) 31 July, (b) 5 August, and (c) 8 August flights, respectively. Ice water content (IWC) data on the 31 July flight has discontinuities relative to $\mathrm{HNO}_{3}$ that are ignored for plotting. Pressure altitude (dashed gray) and longitude (solid thin) are shown for spatial reference. 
a)

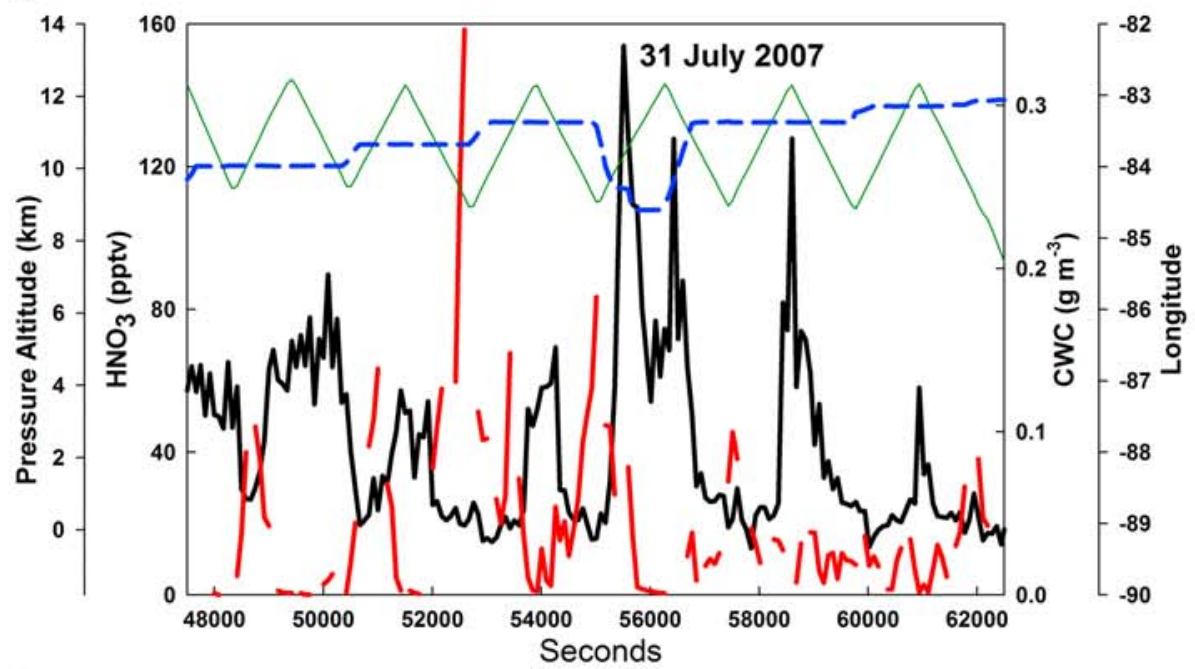

b)

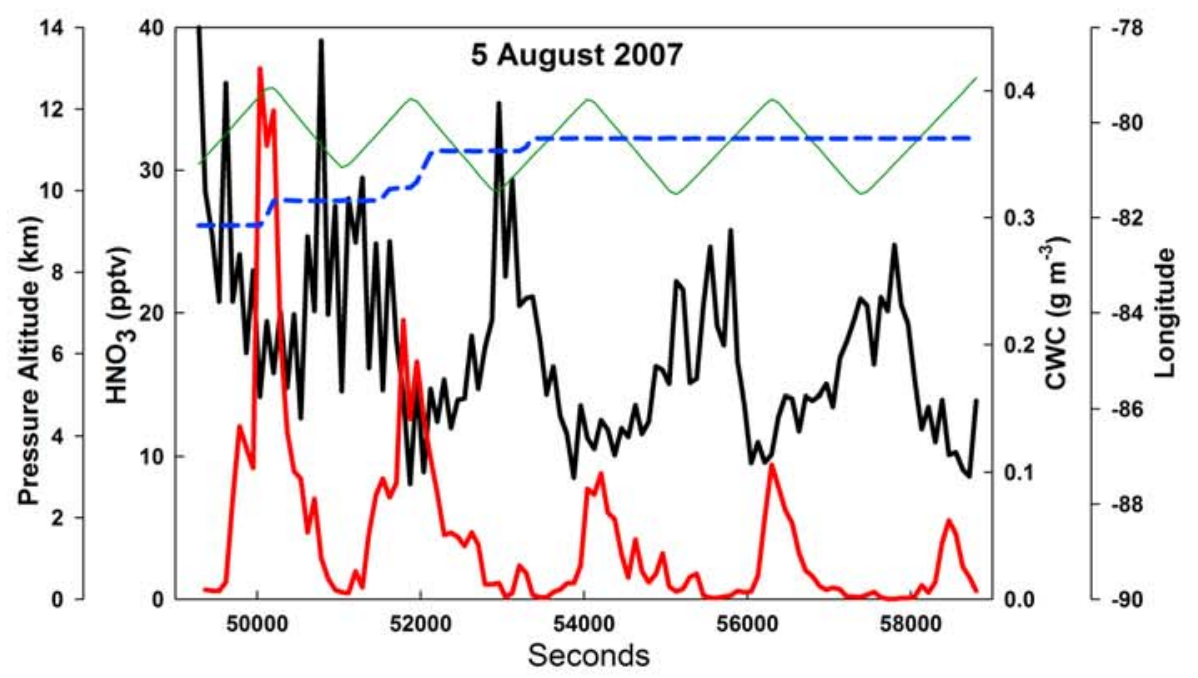

c)

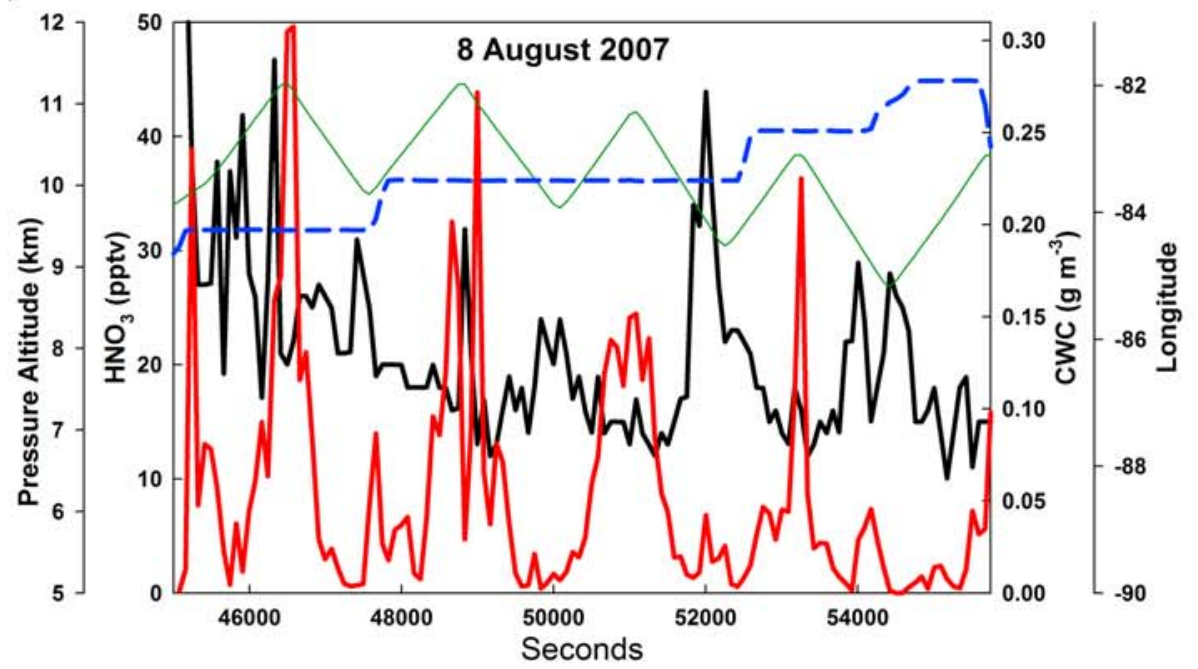

Figure 2 


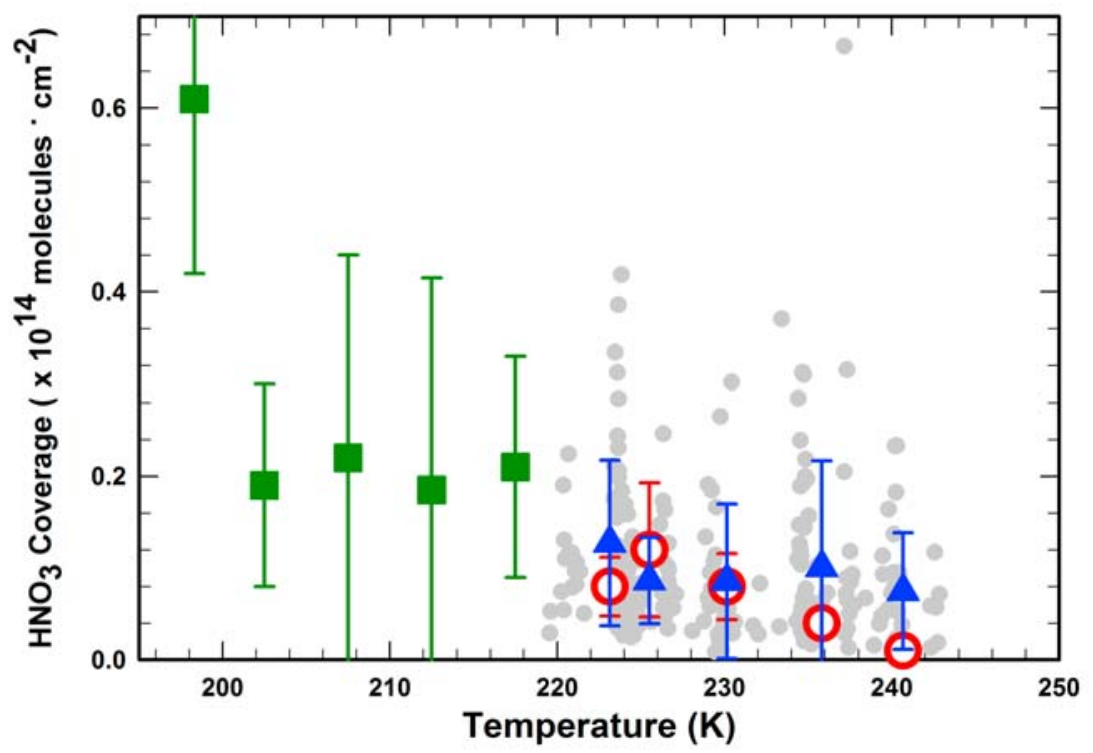

Figure 3. $\mathrm{HNO}_{3}$ molecular coverage versus temperature. Solid gray circles represent discrete values calculated while in cirrus cloud during TC4 flights on 31 July and 5 and 8 August using surface area density (SAD) averaged to $\mathrm{HNO}_{3}$ integration periods, measured $\mathrm{HNO}_{3}$ mixing rations, and an assumed cirrus-free 100 pptv background $\mathrm{HNO}_{3}$ mixing ratio. Blue triangles represent average TC4 coverages for $5^{\circ}$ temperature bins $\sim 219$ to $\sim 243 \mathrm{~K}$. Green squares represent average coverages from Popp et al. [2004, Figure 10] calculated for SADs greater than $200 \mu \mathrm{m}^{2} \mathrm{~cm}^{-3}$ from data obtained during the CRYSTALFACE campaign. Error bars represent one standard deviation of the mean in each temperature bin. Open red circles represent mean predicted molecular coverages predicted using the Langmuir isotherm model presented by Ullerstam et al. [2005] and discrete TC4 $\mathrm{HNO}_{3}$ partial pressure and temperature measurements from each $\sim 85 \mathrm{~s}$ long sample interval.

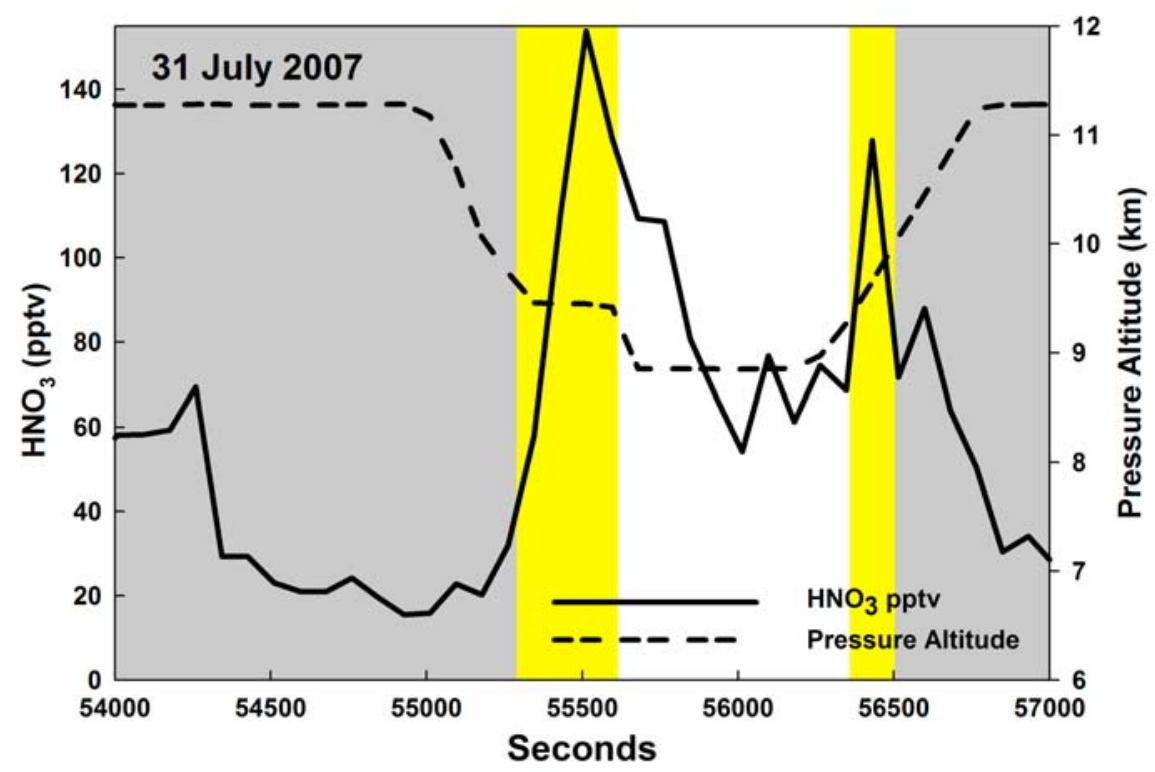

Figure 4. Time series plot from $t=54,000 \mathrm{~s}$ to $t=57,000 \mathrm{~s}$ on the 31 July flight showing enhanced layer of gas-phase $\mathrm{HNO}_{3}$ just below the visible cloud base. $\mathrm{HNO}_{3}$ mixing ratios decreased by a factor of 2 during the subsequent descent to $\sim 0.5 \mathrm{~km}$ below the cloud base. The enhanced layer was also sampled during ascent back into the clouds. 
Table 1. Mean In-Cloud Ice Surface Area Density and Estimated Mean $\mathrm{HNO}_{3}$ Molecular Coverage During Racetrack Maneuvers From TC4 Flights on 31 July and 5 and 8 August

\begin{tabular}{cccc}
\hline Temperature Bin & $\begin{array}{c}\text { Mean } \\
\text { Temperature } \\
(\mathrm{K})\end{array}$ & $\begin{array}{c}\text { Surface } \\
\text { Area } \times 10^{13} \\
\left(\text { molecules } \mathrm{cm}^{-2}\right)\end{array}$ & $\begin{array}{c}\text { Ice Surface } \\
\text { Area Density } \\
\left(\mu \mathrm{m}^{2} \mathrm{~cm}^{-3}\right)\end{array}$ \\
\hline $219-224$ & 223.1 & 1.3 & 3,507 \\
Standard deviation & 1.2 & 0.9 & 2,558 \\
Range & $219.6-224.0$ & $0.3-4.2$ & $712-10,677$ \\
224-229 & 225.5 & 0.9 & 3,673 \\
Standard deviation & 1.3 & 0.5 & 2,190 \\
Range & $224.0-228.9$ & $0.3-2.5$ & $785-10,701$ \\
229-234 & 230.1 & 0.9 & 6,600 \\
Standard deviation & 1.2 & 0.8 & 6,562 \\
Range & $229.0-233.4$ & $0.1-3.7$ & $412-32,256$ \\
234-239 & 235.8 & 1.0 & 6,591 \\
Standard deviation & 1.3 & 1.2 & 5,414 \\
Range & $234.3-238.9$ & $0.1-6.7$ & $415-23,418$ \\
239+ & 240.7 & 0.7 & 7267 \\
Standard deviation & 1.1 & 0.6 & 7998 \\
Range & $239.3-242.8$ & $0.1-2.3$ & $56-38,344$ \\
\hline
\end{tabular}

low of a background estimate. While 60 pptv is higher than in-cloud observations (consistently $<40$ pptv on the last five orbits of the 31 July flight and all orbits on the 5 and 8 August flights) it is indeed only half the mission mean (excluding transit flights to and from Costa Rica) of 120 pptv in the larger subtropical study region UT. Based on this, we assume background mixing ratios of $\mathrm{HNO}_{3}$ in the UT near Costa Rica into which deep convection was detraining were likely in this range of 60-120 pptv. In the following it is assumed that $100 \mathrm{pptv}$ is a reasonable estimate of $\mathrm{UT}_{\mathrm{HNO}}$ before the cirrus formed. This is consistent with the value given by Kärcher and Voigt [2006] as an average over many other field campaigns and was subsequently used by Krämer et al. [2008] in their model of $\mathrm{HNO}_{3}$ partitioning in cirrus clouds. In-cirrus $\mathrm{HNO}_{3}$ was observed at 5-75\% of this assumed background, most often in the range 10-40\% (Figure 2). Noted earlier, the depressed mixing ratios in the anvils could be attributed to simple mixing of background UT air and recently convected air that had $\mathrm{HNO}_{3}$ removed by scavenging. However, if we accept the convected fraction estimate from Avery et al. (submitted manuscript, 2010), this would still yield $\mathrm{HNO}_{3}$ mixing ratios $\sim 50$ pptv in the lower parts of the anvils sampled by the DC-8. Alternatively, we postulate that uptake onto cirrus ice accounts for much of the observed depletion of $\mathrm{HNO}_{3}$ and that at DC-8 flight levels. While contributions from mixing are not being ruled out, disregarding it provides constraint on the maximum uptake of $\mathrm{HNO}_{3}$ onto the cirrus particles in the warm ITCZ clouds.

[14] The inferred uptake onto cirrus ice is simply the 100 pptv background minus observed in-cloud $\mathrm{HNO}_{3}$ mixing ratio. This value was calculated for each $\mathrm{HNO}_{3}$ sample interval when IWC was detectable. The delta $\mathrm{HNO}_{3}$ was converted to volumetric number density using in situ pressure and temperature and then divided by mean observed SAD over each integration interval. Surface coverages of 0.01 to $0.67 \times 10^{14}$ molecules $\mathrm{cm}^{-2}$ were estimated, with substantial scatter (Figure 3, solid gray circles). To examine temperature dependence, we estimated average surface coverages in 5 degree $\mathrm{K}$ temperature bins ranging from $~ 219$ to $\sim 243 \mathrm{~K}$. Table 1 and Figure 3 (blue triangles) suggest twofold more uptake at the coldest temperature compared to the warmest, but the trend is not smooth or statistically significant. We note, however, that the estimated coverages during TC4 are quite similar to those reported by Ziereis et al. [2004] for temperatures of $\sim 227 \mathrm{~K}$ and substantially smaller than all previous observations at temperatures below $220 \mathrm{~K}$ except for the anomalously low coverages reported by Meilinger et al. [1999] at $196 \mathrm{~K}$. The TC4 surface coverage estimates are plotted with the temperature-bin-average $\mathrm{HNO}_{3}$ molecular coverages from CRYSTAL-FACE reported by Popp et al. [2004] from $\sim 198$ to $\sim 218 \mathrm{~K}$ to show the full range of temperatures for which field observations have been reported (Figure 3 ). In addition, we used the nondissociative Langmuir isotherm fit from the Ullerstam et al. [2005] laboratory experiments to predict surface molecular coverages for each TC4 sample,

$$
\Theta=\Theta_{\max } \times \frac{\left(K_{e q} P\right)^{\nu}}{1+\left(K_{e q} P\right)^{\nu}}
$$

where $\nu=1$ (nondissociative isotherm) and $K_{e q}$ is the temperature-dependent equilibrium constant from Ullerstam et al. [2005],

$$
K_{e q}=-(5.1 \pm 0.4) \times 10^{5} T+(12.3 \pm 0.9) \times 10^{7}
$$

assuming $\Theta_{\max }=2.4 \times 10^{14}$ molecules $\mathrm{cm}^{-2}$ as found in the thin film studies. We calculated predicted $\Theta$ during the racetrack anvil encounters using observations of gas-phase $\mathrm{HNO}_{3}$ partial pressure and temperature for each $\sim 85 \mathrm{~s}$ measurement interval. We then calculated average $\Theta$ values for the same 5 discrete temperature bins between $\sim 219$ and $\sim 243 \mathrm{~K}$. Results are shown as red circles in Figure 3.

[15] The Ullerstam et al. [2005] nondissociative isotherm model appears to capture our estimates of $\mathrm{HNO}_{3}$ uptake onto ices surface in the tropical cirrus anvils in the TC4 study regions of the intertropical convergence zone very well. This is a departure from many previous field studies where coverages predicted by isotherm models were often a factor of two or more higher than estimates based on the observations (noted by Ullerstam et al. [2005]). Because the surface coverage estimates based on decreased $\mathrm{HNO}_{3}$ neglect mixing with scavenged air, the means in the 5 temperature bins have to be upper limits. However, if the estimated coverages were reduced by half (on average) to account for dilution, the means would be even closer to those estimated by the isotherm model in 3 of the 5 temperature bins, and the one standard deviation error bars would still overlap in all of the bins. The very low $\mathrm{HNO}_{3}$ vapor pressures and high SAD encountered in the TC4 study region may have led to a system more closely reflecting the equilibrium required for the isotherm model to be applicable. Reported $\mathrm{HNO}_{3}$ vapor pressures in the study region of most prior field campaigns were typically much higher than observed here.

[16] On the other hand, even though the two estimates of surface coverage in the TC4 clouds agree statistically, our estimates based on the apparent loss of gas-phase $\mathrm{HNO}_{3}$ show little or no dependence on temperature, while coverages estimated from the isotherm model markedly decrease above $225 \mathrm{~K}$. It should also be noted that there is considerably more scatter in estimates based on measured $\mathrm{HNO}_{3}$ and SAD than those based on measured $\mathrm{HNO}_{3}$ and $\mathrm{K}$ 


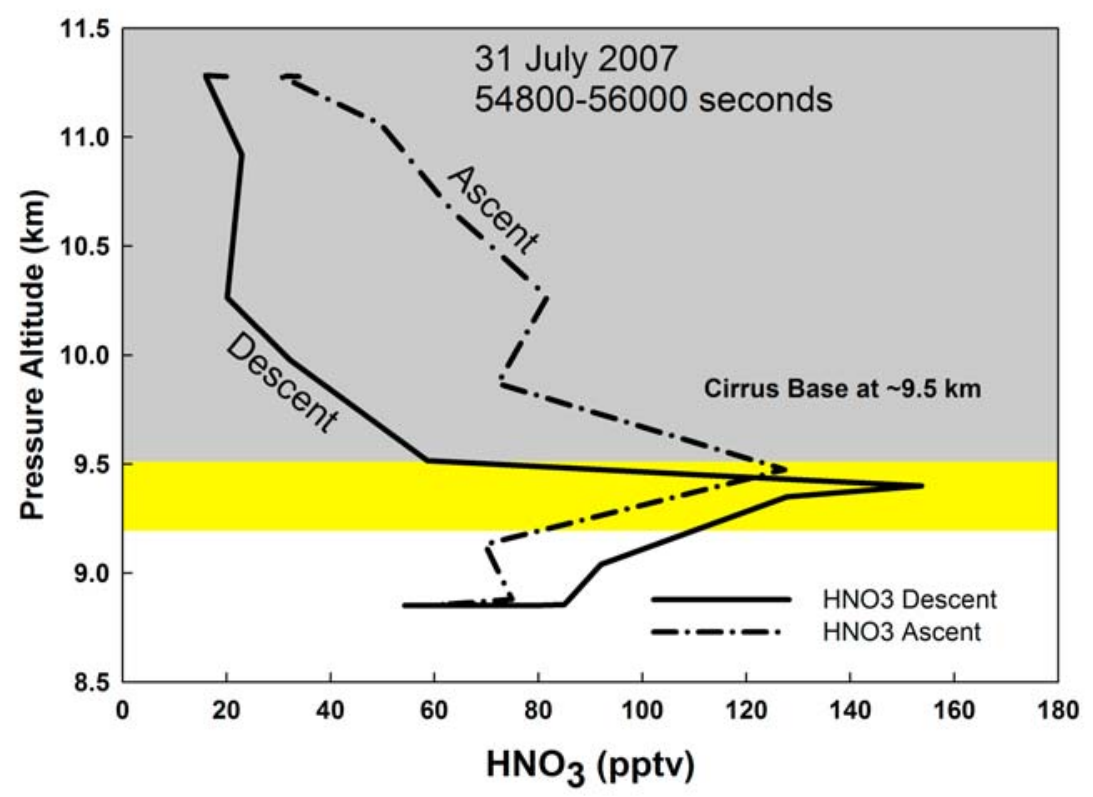

Figure 5. Vertical profile of gas-phase $\mathrm{HNO}_{3}$ from the 31 July flight from $t=54,800 \mathrm{~s}$ to $t=56,000 \mathrm{~s}$. The enhanced layer can be clearly seen during both descent and ascent just below $9.5 \mathrm{~km}$, immediately below the visible base of the cirrus anvil.

in each of the temperature bins (Figure 3), reflecting the key role of available surface area. Ullerstam et al. [2005] pointed out that the fact that cirrus crystals are rarely stable in size (constantly growing or shrinking in response to the local water vapor field) was a likely contributor to the disagreement between laboratory-based models and real clouds. Likewise, Popp et al. [2004] suggested that shortcomings of equilibrium model approaches can be explained, in part, by significant variations in $\mathrm{HNO}_{3}$ mixing ratios in and around cirrus. In particular, settling of ice crystals will generally quickly remove them from any region where they may have been near to equilibrium. Evidence of such particle settling (and release of $\mathrm{HNO}_{3}$ that had been adsorbed at higher altitude) during TC4 is presented in section 4.3. It appears that the agreement between our estimates of surface coverage and estimates based on the isotherm model was more likely fortuitous, than an indication that the TC4 tropical cirrus anvils were generally closer to equilibrium than clouds sampled in previous experiments. The extensive sampling time spent in these clouds allowed averaging over a large number of air masses that were each likely not truly in equilibrium, but to differing degrees.

[17] The estimated surface coverages of $\mathrm{HNO}_{3}$ on cirrus ice during TC4 represent fractional coverages up to $28 \%$ of a molecular monolayer $(\Theta)$ for an extreme case (based on $2.4 \times 10^{14}$ molecules $\mathrm{cm}^{-2}$ from Ullerstam et al. [2005]), with the bin means (Table 1) only ranging from 3 to $5 \%$. Clearly, uptake does not result in monolayer coverages in these warm clouds, especially considering that our estimates are based on the assumption that all of the observed depletion of gas-phase $\mathrm{HNO}_{3}$ is attributed to uptake by ice. Conversely, the depression of $\mathrm{HNO}_{3}$ mixing ratios in the cirrus was substantial (on the order of 60-90\%) and might have implications for chemistry in the UT if the removal was irreversible. However, the dip below cloud base dis- cussed in section 4.3 during the 31 July flight suggests that vertical redistribution of $\mathrm{HNO}_{3}$ by sedimenting cirrus ice may involve only modest displacements.

\subsection{Vertical Redistribution of Nitric Acid by Cirrus}

[18] Sedimentation of cirrus ice crystals with adsorbed $\mathrm{HNO}_{3}$ has been postulated as an efficient mechanism to remove $\mathrm{HNO}_{3}$ from the UT [Lawrence and Crutzen, 1998]. Tropical cirrus have been suggested to have the highest potential to vertically redistribute $\mathrm{HNO}_{3}$ [Krämer et al., 2008]. This occurs when cirrus ice particles grow large enough for gravitational settling to remove them from the cirrus cloud. As ice particles settle out of the cloud into much dryer air below, sublimation releases adsorbed $\mathrm{HNO}_{3}$ taken up in the cloud into the below-cloud air. A key question is how far downward the particles carry the $\mathrm{HNO}_{3}$ before release. As noted earlier, about halfway through the series of orbits during the 31 July flight the DC-8 slowly descended to the cloud base (Figure 2a). Figure 4 is a detailed view of the time period during the descent below the cloud base. It can be seen that while skimming the cloud base, $\mathrm{HNO}_{3}$ was observed to be enhanced by more than $120 \mathrm{pptv}$ compared to the $20 \mathrm{pptv}$ observed in thick cloud immediately preceding descent. After several minutes of level flight, the aircraft descended an additional $500 \mathrm{~m}$ further below the cloud where $\mathrm{HNO}_{3}$ decreased to about 60 pptv. The aircraft then began a slow ascent and the thin layer of enhanced $\mathrm{HNO}_{3}$ was again observed at the cloud base. Vertical profiles of both ascent and descent are presented in Figure 5. These data are consistent with the hypothesized redistribution of $\mathrm{HNO}_{3}$ by cirrus cloud particle sedimentation and subsequent evaporation as described in depth by Lawrence and Crutzen [1998], however, the layer of enhancement observed here is remarkably thin and extremely close to the cloud base Presumably, larger ice 
crystals like those observed in CRYSTAL-FACE might carry $\mathrm{HNO}_{3}$ further below cloud base [Popp et al., 2004] but vertical redistribution by the cirrus clouds sampled from the DC-8 in TC4 appears limited to the thickness of the cirrus anvil.

\section{Conclusions}

[19] $\mathrm{HNO}_{3}, \mathrm{IWC}$, and SAD observations in warm cirrus anvils ( 219-243 K) during three focused and repeated encounters in the tropical UT near Costa Rica during the NASA TC4 field campaign in 2007 are presented. In-cloud depletions of gas-phase $\mathrm{HNO}_{3}$ were observed and were positively correlated to increasing cloud water content and ice surface area. Based on observations from the same study, we assume that the out-of-cloud $\mathrm{HNO}_{3}$ background mixing ratio is approximately 100 pptv and the difference in observations made while in-cloud represent $\mathrm{HNO}_{3}$ adsorbed onto ice particles. With these assumptions, average molecular coverages of $\mathrm{HNO}_{3}$ on ice particles ranged from $0.7 \times 10^{13}$ to $1.3 \times 10^{13}$ molecules $\mathrm{cm}^{-2}$ for 5 different temperature bins. Our observations suggest that uptake was not limited by available ice surfaces as these coverages represent about 3 to $5 \%$ of a monolayer (assuming $\Theta_{\max }=2.4 \times 10^{14}$ molecules $\mathrm{cm}^{-2}$ ). However, this was enough to effect up to about $90 \%$ depletion of gas-phase $\mathrm{HNO}_{3}$ at periods of high IWC and $\mathrm{SAD}$. Although there is no obvious temperature dependence seen in our molecular surface coverage on ice, our observations appear to be slightly lower than those presented by Popp et al. [2004] from measurements made during CRYSTALFACE in slightly cooler tropical upper tropospheric cirrus cloud. This supports prior laboratory work suggesting a negative temperature dependence on uptake. Evidence of gravitational settling and subsequent evaporation of cirrus ice particles releasing $\mathrm{HNO}_{3}$ back to the gas phase was observed during the 31 July flight, however the magnitude of this single event is not sufficient to support large-scale redistribution of $\mathrm{HNO}_{3}$ similar to that proposed by Lawrence and Crutzen [1998]. Further investigations into the magnitude of the redistributive capabilities of cirrus clouds would benefit from repeated vertical profiles in and beneath such formations and would ideally include direct in situ measurements of both gas-phase and condensed-phase $\mathrm{HNO}_{3}$.

[20] Acknowledgments. TC4 was sponsored by the NASA Headquarters Atmospheric Composition Focus Group which includes the Tropospheric Chemistry Program, Upper Atmospheric Research Program, and Radiation Science Program.

\section{References}

Abbatt, J. P. D. (1997), Interaction of $\mathrm{HNO}_{3}$ with water-ice surfaces at temperatures of the free troposphere, Geophys. Res. Lett., 24(12), 1479-1482, doi:10.1029/97GL01403.

Arora, O. P., D. J. Cziczo, A. M. Morgan, J. P. D. Abbott, and R. F. Niedziela (1999), Uptake of nitric acid by sub-micron-sized ice particles, Geophys. Res. Lett., 26(24), 3621-3624, doi:10.1029/1999GL010881.

Bertram, T. H., et al. (2007), Direct measurements of the convective recycling of the upper troposphere, Science, 315(5813), 816-820, doi: $10.1126 /$ science. 1134548 .

Field, P. R., A. J. Heymsfield, and A. Bansemer (2006), Shattering and particle interarrival times measured by optical array probes in ice clouds, J. Atmos. Oceanic Technol., 23, 1357-1371, doi:10.1175/JTECH1922.1.

Hinds, W. C. (1982), Acceleration and curvilinear particle motion, in Aerosol Technology: Properties, Behavior, and Measurement of Airborne Particles, pp. 105-110, John Wiley, New York.
Hudman, R. C., et al. (2007), Surface and lightning sources of nitrogen oxides over the United States: Magnitudes, chemical evolution, and outflow, J. Geophys. Res., 112, D12S05, doi:10.1029/2006JD007912.

Hudson, P. K., J. E. Shilling, M. A. Tolbert, and O. B. Toon (2002), Uptake of nitric acid on ice at tropospheric temperatures: Implications for cirrus clouds, J. Phys. Chem. A, 106, 9874-9882, doi:10.1021/jp020508j.

Hynes, R. G., M. A. Fernandez, and R. A. Cox (2002), Uptake of $\mathrm{HNO}_{3}$ on water-ice and coadsorption of $\mathrm{HNO}_{3}$ and $\mathrm{HCl}$ in the temperature range 210-235 K, J. Geophys. Res., 107(D24), 4797, doi:10.1029/ 2001JD001557.

Jacob, D. J., et al. (1996), Origin of ozone and $\mathrm{NO}_{\mathrm{x}}$ in the tropical troposphere: A photochemical analysis of aircraft observations over the South Atlantic basin, J. Geophys. Res., 101(D19), 24,235-24,250, doi:10.1029/ 96JD00336.

Jensen, E. J., et al. (2009), On the importance of small ice crystals in tropical anvil cirrus, Atmos. Chem. Phys. Discuss., 9, 5321-5370.

Kärcher, B., and C. Voigt (2006), Formation of nitric acid/water ice particles in cirrus clouds, Geophys. Res. Lett., 33, L08806, doi:10.1029/ 2006 GL025927.

Kondo, Y., et al. (2003), Uptake of reactive nitrogen on cirrus cloud particles in the upper troposphere and lowermost stratosphere, Geophys. Res. Lett., 30(4), 1154, doi:10.1029/2002GL016539.

Krämer, M., C. Schiller, C. Voigt, H. Schlager, and P. J. Popp (2008), A climatological view of HNO3 partitioning in cirrus clouds, $Q . J . R$. Meteorol. Soc., 134, 905-912, doi:10.1002/qj.253.

Lawrence, M. G., and P. J. Crutzen (1998), The impact of cloud particle gravitational settling on soluble trace gas distributions, Tellus, Ser. B, 50, 263-289, doi:10.1034/j.1600-0889.1998.t01-2-00005.x.

Meier, A., and J. Hendricks (2002), Model studies on the sensitivity of upper tropospheric chemistry to heterogeneous uptake of $\mathrm{HNO}_{3}$ on cirrus ice particles, J. Geophys. Res., 107(D23), 4696, doi:10.1029/ 2001JD000735.

Meilinger, S. K., et al. (1999), $\mathrm{HNO}_{3}$ partitioning in cirrus clouds, Geophys. Res. Lett., 26(14), 2207-2210, doi:10.1029/1999GL900423.

Neuman, J. A., et al. (2001), In situ measurements of $\mathrm{HNO}_{3}, \mathrm{NO}_{\mathrm{y}}, \mathrm{NO}$, and $\mathrm{O}_{3}$ in the lower stratosphere and upper troposphere, Atmos. Environ., 35(33), 5789-5797, doi:10.1016/S1352-2310(01)00354-5.

Pierce, R. B., et al. (2007), Chemical data assimilation estimates of continental U.S. ozone and nitrogen budgets during the Intercontinental Chemical Transport Experiment-North America, J. Geophys. Res., 112, D12S21, doi:10.1029/2006JD007722.

Popp, P. J., et al. (2004), Nitric acid uptake on subtropical cirrus cloud particles, J. Geophys. Res., 109, D06302, doi:10.1029/2003JD004255.

Staudt, A. C., D. J. Jacob, F. Ravetta, J. A. Logan, D. Bachiochi, T. N. Krishnamurti, S. Sandholm, B. Ridley, H. B. Singh, and B. Talbot (2003), Sources and chemistry of nitrogen oxides over the tropical Pacific, J. Geophys. Res., 108(D2), 8239, doi:10.1029/2002JD002139.

Tabazadeh, A., O. B. Toon, and E. J. Jensen (1999), A surface chemistry model for nonreactive trace gas adsorption on ice: Implications for nitric acid scavenging by cirrus, Geophys. Res. Lett., 26(14), 2211-2214, doi:10.1029/1999GL900501.

Thakur, A. N., H. B. Singh, P. Mariani, Y. Chen, Y. Wang, D. J. Jacob, G. Brasseur, J. F. Muller, and M. Lawrence (1999), Distribution of reactive nitrogen species in the remote free troposphere: Data and model comparisons, Atmos. Environ., 33(9), 1403-1422, doi:10.1016/ S1352-2310(98)00281-7.

Tian, L., G. M. Heymsfield, A. J. Heymsfield, A. Bansemer, L. Li, C. H. Twohy, and R. C. Srivastava (2010), A study of cirrus ice particle size distribution using TC4 observations, J. Atmos. Sci., 67, 195-216.

Toon, O. B., et al. (2010), Planning, implementation and first results of the Tropical Composition, Cloud, and Climate Coupling Experiment (TC4), J. Geophys. Res., doi:10.1029/2009JD013073, in press.

Twohy, C. H., A. J. Schanot, and W. A. Cooper (1997), Measurement of condensed water content in liquid and ice clouds using an airborne counterflow virtual impactor, J. Atmos. Oceanic Technol., 14(1), 197-202, doi:10.1175/1520-0426(1997)014<0197:MOCWCI>2.0.CO;2.

Ullerstam, M., T. Thornberry, and J. P. D. Abbatt (2005), Uptake of gasphase nitric acid to ice at low partial pressures: Evidence for unsaturated surface coverage, Faraday Discuss., 130, 211-226, doi:10.1039/ b417418f.

Weinheimer, A. J., T. L. Campos, J. G. Walega, F. E. Grahek, B. A. Ridley, D. Baumgardner, C. H. Twohy, B. Gandrud, and E. J. Jensen (1998), Uptake of $\mathrm{NO}_{\mathrm{y}}$ on wave-cloud ice particles, Geophys. Res. Lett., 25 (10), 1725-1728, doi:10.1029/97GL02957.

Ziereis, H., et al. (2004), Uptake of reactive nitrogen on cirrus cloud particles during INCA, Geophys. Res. Lett., 31, L05115, doi:10.1029/ 2003 GL018794. 
Zondlo, M. A., S. B. Barone, and M. A. Tolbert (1997), Uptake of $\mathrm{HNO}_{3}$ on ice under upper tropospheric conditions, Geophys. Res. Lett., 24(11), 1391-1394, doi:10.1029/97GL01287.

A. Bansemer and A. J. Heymsfield, Earth and Sun Systems Laboratory, National Center for Atmospheric Research, 3450 Mitchell Ln., Boulder, CO 80301, USA.
J. E. Dibb and E. Scheuer, Institute for the Study of Earth, Oceans and Space, University of New Hampshire, 8 College Rd., Durham, NH 03824, USA. (eric.scheuer@unh.edu)

D. C. Rogers, Research Aviation Facility, National Center for Atmospheric Research, 10802 Airport Ct., Broomfield, CO 80021, USA.

C. Twohy, College of Oceanic and Atmospheric Sciences, Oregon State University, Corvallis, OR 97331, USA. 